\title{
PARP inhibition in UV-associated angiosarcoma preclinical models
}

\author{
Marije E. Weidema ${ }^{1}$ (D . Ingrid M. E. Desar ${ }^{1} \cdot$ Melissa H. S. Hillebrandt-Roeffen ${ }^{1} \cdot$ Anke E. M. van Erp ${ }^{1}$. \\ Mikio Masuzawa ${ }^{2}$. PALGA-group · Uta E. Flucke ${ }^{3}$ - Winette T. A. van der Graaf ${ }^{4}$ - Yvonne M. H. Versleijen-Jonkers ${ }^{1}$
}

Received: 17 April 2021 / Accepted: 27 May 2021 / Published online: 3 June 2021

(c) The Author(s) 2021

\begin{abstract}
Purpose Angiosarcoma (AS) is a rare vasoformative sarcoma, with poor overall survival and a high need for novel treatment options. Clinically, AS consists of different subtypes, including AS related to previous UV exposure (UV AS) which could indicate susceptibility to DNA damage repair inhibition. We, therefore, investigated the presence of biomarkers PARP1 (poly(ADP-ribose)polymerase-1) and Schlafen-11 (SLFN11) in UV AS. Based on experiences in other sarcomas, we examined (combination) treatment of PARP inhibitor (PARPi) olaparib and temozolomide (TMZ) in UV AS cell lines. Methods Previously collected UV AS $(n=47)$ and non-UV AS $(n=96)$ patient samples and two UV AS cell lines (MOLAS and AS-M) were immunohistochemically assessed for PARP1 and SLFN11 expression. Both cell lines were treated with single agents PARPi olaparib and TMZ, and the combination treatment. Next, cell viability and treatment synergy were analyzed. In addition, effects on apoptosis and DNA damage were examined.

Results In 46/47 UV AS samples (98\%), PARP1 expression was present. SLFN11 was expressed in 80\% (37/46) of cases. Olaparib and TMZ combination treatment was synergistic in both cell lines, with significantly increased apoptosis compared to single agent treatment. Furthermore, a significant increase in DNA damage marker $\gamma \mathrm{H} 2 \mathrm{AX}$ was present in both cell lines after combination therapy.

Conclusion We showed combination treatment of olaparib with TMZ was synergistic in UV AS cell lines. Expression of PARP1 and SLFN11 was present in the majority of UV AS tumor samples. Together, these results suggest combination treatment of olaparib and TMZ is a potential novel AS subtype-specific treatment option for UV AS patients.
\end{abstract}

Keywords Angiosarcoma $\cdot$ Subtype $\cdot$ PARP $\cdot$ Temozolomide $\cdot$ Combination treatment $\cdot$ SLFN11

\section{Introduction}

Angiosarcoma (AS) is a rare sarcoma with endothelial properties and an incidence of 0.15 per 100.000 persons per year (NCIN 2012). AS can occur either sporadically (primary

The members of PALGA-group are list in "Acknowledgements".

Marije E. Weidema

Marije.Weidema@radboudumc.nl

1 Department of Medical Oncology, Radboud University Medical Center, Internal Postal Code 452, P.O. Box 9101, 6500 HB Nijmegen, The Netherlands

2 Department of Regulation Biochemistry, Kitasato University School of Allied Sciences, Sagamihara, Japan

3 Department of Pathology, Radboud University Medical Center, Nijmegen, The Netherlands

4 Department of Medical Oncology, Netherlands Cancer Institute, Amsterdam, The Netherlands
AS) or due to external damaging factors such as UV exposure, radiation therapy or chronic lymphedema (secondary AS). Localized AS treatment consists of surgery, combined with (neo-)adjuvant radiation therapy or chemotherapy. Patients with metastatic disease usually receive chemotherapy, either anthracycline-based regimens or paclitaxel (Penel et al. 2012). Later lines of treatment can include other chemotherapeutic agents such as gemcitabine (Stacchiotti et al. 2012) or targeted therapy with pazopanib (van der Graaf et al. 2012; Kollar et al. 2017). Reported overall survival (OS) of all AS patients is poor with a 5-year survival rate of around 22-40\% (Lahat et al. 2010; Wang et al. 2017; Weidema et al. 2019), dropping to only $15 \%$ for metastatic patients (Lahat et al. 2010). To improve AS prognosis, several targeted treatment strategies have been explored, such as bevacizumab or sorafenib (Agulnik et al. 2013; Ray-Coquard et al. 2012). Recently, small case series have suggested a role for immunotherapy in selected AS patients (Painter et al. 
2020; Florou et al. 2019). Although these results are promising, these efforts have yet to result in clinical implications for current AS patients.

Over the past decades, AS patient survival has not improved, emphasizing the need for more effective treatment options (Zhang et al. 2019). As a start, more in-depth knowledge on the molecular characteristics of the different AS subtypes would be instrumental for further research (Chan et al. 2020; Painter et al. 2020; Weidema et al. 2020). A recent study provided evidence for the role of UV-induced DNA damage in a subset of AS, showing that 10/12 (83\%) cutaneous AS originating in the head and neck region harbored a genetic UV signature (Painter et al. 2020). The fact that UV-associated AS develop due to DNA damage, gave rise to the hypothesis that these tumors could be particularly susceptible to inhibition of the DNA damage response (DDR) pathway.

The DDR machinery includes base excision repair (BER); a major pathway involved in among others repair of DNA single strand breaks (SSBs) generated by reactive oxygen species, ionizing radiation and alkylating agents (Zhang et al. 2012). A key protein in the BER pathway is poly(ADPribose) polymerase-1 (PARP1), which initiates repair by detection of SSBs (Lord and Ashworth 2012). Upon binding of PARP1 to the SSB, PARP1 initiates formation of poly ADP-ribose (pADPr) chains. Both PARP1 and the pADPr chains then attract proteins to form the BER complex. Next, release of PARP1 from the damaged DNA allows access for BER proteins to the damaged site, thus enabling repair. Upon PARP inhibition, SSB repair is compromised leading to persistent SSBs. In addition, release of PARP1 from the DNA is inhibited (so-called PARP trapping). Both persistent SSBs as well as PARP trapping can stall replication forks, potentially resulting in lethal double-strand breaks (DSBs).

In case of defects in the repair of DSBs, for instance in BRCA-mutated cancers, PARP inhibitor (PARPi) monotherapy can already effectively cause cell death (Farmer et al. 2005). However, in malignancies without such defects, clinical application of PARPi monotherapy was shown to have only limited efficacy (Choy et al. 2014; Leichman et al. 2016). PARP inhibitors have been shown to synergize with different kinds of chemotherapeutic agents. Of these drugs, TMZ induces SSBs and causes increased PARP trapping when combined with a PARPi (Murai et al. 2014), and combination therapy of PARPi with TMZ has shown promising results in vitro and in vivo in other sarcomas, such as Ewing sarcoma, desmoplastic small round cell tumors and chordoma (Smith et al. 2015; Cao et al. 2019; van Erp et al. 2020). We hypothesized that combination treatment of a PARPi with TMZ would be of particular interest in UV AS, based on the UV-induced DNA damage already present in the cells, as well as additional DNA damage inflicted by TMZ.
To assess the potential of this combination in UV AS, we aimed to study the presence of biomarkers for response. PARP1 expression was shown to be predictive of response to combination treatment of PARPi olaparib with trabectedin and other cytotoxic agents across different cell lines (Pignochino et al. 2017). In addition, PARP1 expression was shown to be crucial for response to PARPi, as PARP1 knockdown made cells highly resistant to PARP inhibition (Murai et al. 2012). Schlafen-11 (SLFN11) is an even more interesting potential biomarker. It is recruited to stressed replication forks, then opens chromatin and thus induces a permanent and lethal replication block in cells under replication stress (Murai et al. 2018). Based on this mechanism, SLFN11 is a biomarker for response to agents causing replicative stress, including PARP inhibitors (Zoppoli et al. 2012; Barretina et al. 2012; Murai et al. 2016). Knockdown of SLFN11 has shown to result in decreased sensitivity to the DNA damaging cytotoxic agent trabectedin in preclinical liposarcoma and Ewing sarcoma (ES) models (Iwasaki et al. 2019) and decreased sensitivity to the PARPi talazoparib in small cell lung cancer (SCLC) cell lines (Lok et al. 2017). As for the combination therapy of PARPi and TMZ, SLFN11 expression appears to mainly correlate with sensitivity to PARPi treatment, however, in mesothelioma cell lines and SCLC in vivo models SLFN11 expression also correlated with increased response to PARPi and TMZ combination treatment (Lok et al. 2017; Rathkey et al. 2020). Furthermore, resistance to the combination of TMZ with PARPi niraparib was shown after SLFN11 knockdown in ES cells (Tang et al. 2015).

We, therefore, aimed to assess the presence of PARP1 and SLFN11 protein expression in clinically derived tumor tissue of UV AS and non-UV AS cases. Next, we investigated whether combination therapy of TMZ and PARPi olaparib is effective in preclinical in vitro UV AS models.

\section{Materials and methods}

\section{Immunohistochemical PARP1 and SLFN11 expression in patient-derived AS tumor tissue}

In a previous study, AS cases and clinical data were collected via a nationwide query in The Netherlands (1989-2014) using the Netherlands Cancer Registry (NCR) (Weidema et al. 2019). Through linkage with the Dutch Nationwide Network and Registry of Histo- and Cytopathology (PALGA), AS tumor samples were collected for pathology review (Casparie et al. 2007). Confirmed AS cases were categorized based on clinical origin, with all cutaneous AS from the sun-exposed skin of the head and neck region classified as UV-associated. Non-UV AS cases were classified according to clinical subtype; including 
radiotherapy-induced, cutaneous non-UV associated, Stewart Treves (associated with chronic lymphedema) and visceral angiosarcoma. From tissue microarrays (TMAs), constructed from formalin-fixed, paraffin-embedded (FFPE) material of AS cases of which sufficient tumor was available with one or two $2.0 \mathrm{mM}$ cores per tumor sample from representative tumor areas, $4 \mu \mathrm{M}$ thick slides were assessed for PARP1 and SLFN11 expression. For PARP1, colon and tonsil tissue served as positive control. For SLFN11, tonsil and a xenograft of a human Ewing sarcoma served as positive control. Sections were deparaffinized in xylene and rehydrated through a graded ethanol into water series. Antigen retrieval was performed by heating the slides in EDTA buffer, pH9 for $10 \mathrm{~min}$ (PARP1) or $20 \mathrm{~min}$ (SLFN11) at $100{ }^{\circ} \mathrm{C}$. Endogenous peroxidase activity was blocked with $3 \% \mathrm{H}_{2} \mathrm{O}_{2}$ in distilled water for $10 \mathrm{~min}$ at room temperature. Subsequently, sections were incubated with monoclonal rabbit anti-PARP1 antibody (1:800, clone E102, Abcam, Cambridge, UK) or monoclonal rabbit anti-SLFN11 antibody (1:100, clone D8W1B, Cell Signaling Technology, Leiden, The Netherlands) in antibody diluent in a humidified chamber overnight at $4{ }^{\circ} \mathrm{C}$. Next, tissue sections were incubated with Poly-HRP-GAMs/Rb IgG (ImmunoLogic, Duiven, The Netherlands) in EnVision ${ }^{\text {TM }}$ FLEX Wash Buffer (Dako, Agilent Technologies, Santa Clara, CA, USA) (1:1) for $30 \mathrm{~min}$ at room temperature. Antibody binding was visualized using the EnVision ${ }^{\mathrm{TM}}$ FLEX Substrate Working Solution (Dako) for $10 \mathrm{~min}$ at room temperature. Finally, slides were counterstained with haematoxylin, dehydrated and coverslipped.

After validation, all IHC stainings were scored by two independent observers. For PARP1 and SLFN11, cores with $>50 \%$ tumor cells with positive nuclear staining were regarded positive. In case of a discrepancy between two cores derived from one patient, the highest score was applied, whereas in case of observer discrepancies, a third observer was consulted. Correlation analysis to assess the correlation between SLFN11 and PARP1 expression was performed using the Fisher's exact test, with IBM SPSS Statistics (Armonk, NY, USA), version 25.0.0.1. This study was performed in accordance with the Code of Conduct of the Federation of Medical Scientific Societies in The Netherlands.

\section{Cell lines, cell culture and compounds}

Human cutaneous scalp AS cell line MO-LAS was generously provided by Dr. Masuzawa from the Kitasato University School of Allied Sciences, Sagamihara, Japan (Masuzawa et al. 2012). MO-LAS cells were cultured in Dulbecco's Modified Eagle's Medium (DMEM, Lonza, The Netherlands) supplemented with $10 \%$ Fetal Bovine Serum (FBS, Gibco, Thermo Fisher Scientific, Waltham, MA, USA) and $1 \%$ penicillin-streptomycin (Gibco). Human cutaneous scalp AS cell line AS-M was generously provided by Prof. Kirkpatrick and Dr. Unger from Johannes Gutenberg University, Mainz, Germany (Krump-Konvalinkova et al. 2003). AS-M cells were cultured in Endothelium Cell Growth Medium MV (ECGM MV, PromoCell, Heidelberg, Germany) and $1 \%$ penicillin-streptomycin. Similar to the tumor samples, both cell lines originated from sun-exposed skin of the scalp. Both MO-LAS and AS-M cells were kept in a humidified atmosphere of $5 \% \mathrm{CO}_{2} / 95 \%$ air at $37{ }^{\circ} \mathrm{C}$. TMZ and olaparib were purchased from Selleckchem (Houston, TX, USA) and diluted in DMSO for in vitro experiments. Experiments were performed in triplicate.

\section{Cell viability assay}

Cell viability was assessed using the MTT assay. Cells were seeded in quadruplicate in a 96 -wells plate (3000 cells/well) and allowed to adhere overnight. Cells were then treated in a range of concentrations of TMZ $(0-500 \mu \mathrm{M})$ or olaparib $(0-100 \mu \mathrm{M})$ monotherapy for $144 \mathrm{~h}$. Next, cells were incubated with $5 \mathrm{mg} / \mathrm{ml}$ MTT (Sigma-Aldrich, Saint Louis, MO, USA) in PBS for $3.5 \mathrm{~h}$. The formed formazan crystals were dissolved in MTT solvent (isopropanol, 0.1\% NP-40 and $4 \mathrm{mM}$ fuming hydrochloric acid). Absorbance was measured with a dual measurement at 560 and $655 \mathrm{~nm}$ using the BioRad iMark plate reader (Bio-Rad, Hercules, CA, USA). For each drug the IC50 was calculated using GraphPad Prism software (version 5.03 for Windows, GraphPad Software, San Diego, CA, USA, http://www.graphpad.com).

\section{Drug synergy and combination index}

Drug synergy of combined TMZ and olaparib was assessed by calculation of the combination index $(\mathrm{CI})$ and dose reduction index (DRI) with CompuSyn software (ComboSyn Inc.) using the Chou-Talalay method (Chou 2006). Cells were simultaneously treated with $\mathrm{TMZ}$ and olaparib concentrations in a non-constant ratio for $144 \mathrm{~h}$, combining relatively low dosages of olaparib (using the $\mathrm{IC}_{50}$ and approximately $50 \%$ of the $\mathrm{IC}_{50}$ values) with increasing dosages of TMZ $(10 ; 25 ; 50 ; 100 \mu \mathrm{M})$. Effects on cell viability of the monotherapy and combination therapy were assessed in three independent experiments, using an average fraction of cell viability affected (FA) value for further calculations. Results of the combination treatment are represented in an isobologram, in which the line represents an additive effect $(\mathrm{CI}=1.0)$ of the combination at the given FA value. Points below the line represent synergism $(\mathrm{CI}<1.0)$, points above the line represent antagonism (CI > 1.0) (Chou 2006). More specifically, according to Chou et al., a CI value between 0.3 and 0.7 indicates synergism and CI 0.1-0.3 strong synergism (Chou 2006). The $X$ - and $Y$-axis represent the fraction of the dose necessary 
as a single agent to generate reduction of $x \%$ cell viability $\left(D_{1 / 2}\right)$ divided by the portion of the drug in the combination treatment $\left(D_{1}+D_{2}\right)$ necessary to reduce a similar $x \%$ cell viability $(D x)_{1 / 2}$. DRI values of $>1.0$ indicate a favorable dose reduction in the combination treatment compared to the monotherapy dose. Differences in cell viability following combination treatment were analyzed by two-way ANOVA with Bonferroni post-test using GraphPad Prism software, a $p$ value $<0.05$ was considered significant $(*<0.05, * *<0.01, * * *<0.001)$.

\section{Western blot}

Western blot analysis of $\gamma \mathrm{H} 2 \mathrm{AX}$ was performed to investigate the induction of DNA damage after single agent and combination treatments with low and high dose TMZ. Protein extracts were purified from the MO-LAS and AS-M cell lines after $48 \mathrm{~h}$ with single agent and combination treatment. Cells were incubated in cold RIPA buffer containing protease and phosphatase inhibitors and the lysates were centrifuged at $14,000 \mathrm{~g}$ at $4{ }^{\circ} \mathrm{C}$ for $15 \mathrm{~min}$. Then protein concentrations of the supernatants were determined with the BCA protein assay system (Pierce Endogen, Rockford, IL, USA). Of each condition, equal amounts of protein $(50 \mu \mathrm{g})$ were loaded and run on a $12 \%$ sodium dodecyl sulfate-polyacrylamide gel electrophoresis (SDSPAGE) gel under reducing conditions and subsequently transferred to nitrocellulose membranes. After blocking with Odyssey blockbuffer (LI-COR Biosciences, Lincoln, NE, USA) in TBS (1:1) at room temperature (RT) for $1 \mathrm{~h}$, membranes were incubated overnight at $4{ }^{\circ} \mathrm{C}$ with monoclonal rabbit anti-phospho-Histone $\mathrm{H} 2 \mathrm{~A} . \mathrm{X}(\gamma \mathrm{H} 2 \mathrm{AX}$, Ser139) (1:1000, Cell Signaling Technology, Leiden, The Netherlands). Next, the blots were incubated at room temperature for $1 \mathrm{~h}$ with a goat-anti-rabbit fluor 680-conjugated secondary antibody (1:5000, AlexaFluor, Invitrogen, OR, USA), incubated for $1 \mathrm{~h}$ at RT with monoclonal mouse anti-GAPDH (1:10,000, Abcam, Cambridge, UK) as a loading control and subsequently incubated for $1 \mathrm{~h}$ at RT with a goat-anti-mouse fluor 800-conjugated secondary antibody (1:5000, AlexaFluor, Invitrogen). The fluorescent signals were analyzed with the Odyssey Infrared Imaging System (LI-COR Biosciences) and Odyssey Application Software (version 3.0.30). The experiment was performed in duplicate. In addition, western blot analysis of PARP1 and SLFN11 was performed as described above on the MO-LAS and AS-M cell line, using the monoclonal rabbit anti-PARP1 (\#9542, 1:2000, Cell Signaling Technology), monoclonal rabbit anti-SLFN11 (\#34858, 1:1000, Cell Signaling Technology), and monoclonal mouse anti alpha Tubulin (A11126, 1:1000, Invitrogen).

\section{Apoptosis assay}

Apoptosis was assessed using the Annexin-V/propidium iodide (PI) double staining apoptosis assay (Biovision Cat\# 1001-200, CA, USA) after single agent treatment and combination treatment. Cells were incubated with Annexin-VFITC and PI in cell culture medium supplemented with $\mathrm{CaCl}_{2}$ (final concentration $15 \mathrm{mM}$ ). Apoptotic cells were measured using the CytoFLEX flow cytometer (Beckman-Coulter, Brea, CA, USA) and the percentage of early (Annexin-V positive, PI negative) and late (Annexin-V and PI positive) apoptotic cells was calculated using FlowJo software (version 10.0.7).

\section{Results}

\section{PARP1 and SLFN11 expression in AS tumor tissues}

A total of 47 UV AS patients were assessed for immunohistochemical expression of PARP1 and SLFN11. Median age was 78 years and median overall survival was 13 months (range 0-194 months). Additional clinical characteristics are described in Supplemental Table 1 PARP1 was expressed in $46 / 47$ (98\%) of cases, whereas $80 \%$ (37/46) of tumors showed SLFN11 positivity (Fig. 1, Table 1; Supplemental Fig. 1). In 36 UV AS patients (77\%), both SLFN11 and PARP1 expression was present. None of the UV AS samples was negative for both PARP1 and SLFN11 expression. In addition, tumor samples of 96 non-UV AS patients were assessed for PARP1 and SLFN11 expression, showing $89-100 \%$ PARP1 positivity and $63-66 \%$ cases positive for SLFN11 expression. In all 143 AS cases taken together, SLFN11 and PARP11 expression was significantly correlated ( $p=0.002$, Supplemental Table 2).

Both the MO-LAS and the AS-M cell line showed strong immunohistochemical positivity for PARP1 and SLFN11, as well as presence of PARP1 and SLFN11 by western blot analysis (Supplemental Fig. 2).

\section{Combination treatment of olaparib and TMZ in AS cell lines}

MO-LAS cells showed an $\mathrm{IC}_{50}$-value of $1.99 \pm 0.11 \mu \mathrm{M}$ for olaparib and $110.3 \pm 15.2 \mu \mathrm{M}$ for TMZ (Table 2, Fig. 2a). AS-M cells exhibited a higher $\mathrm{IC}_{50}$-value for olaparib $(6.62 \pm 1.02 \mu \mathrm{M})$, and were more sensitive to TMZ than MO-LAS cells ( $\left.\mathrm{IC}_{50} 66.8 \pm 11.9 \mu \mathrm{M}\right)$ (Fig. 2b). The combination treatment significantly decreased cell viability compared to the single agent treatments in both cell lines (Fig. 3a, b), except for the combination of $1 \mu \mathrm{M}$ olaparib and $10 \mu \mathrm{M}$ TMZ in MO-LAS cells, and $7 \mu \mathrm{M}$ olaparib and $10 \mu \mathrm{M}$ TMZ in AS-M cells. Calculation of the combination 


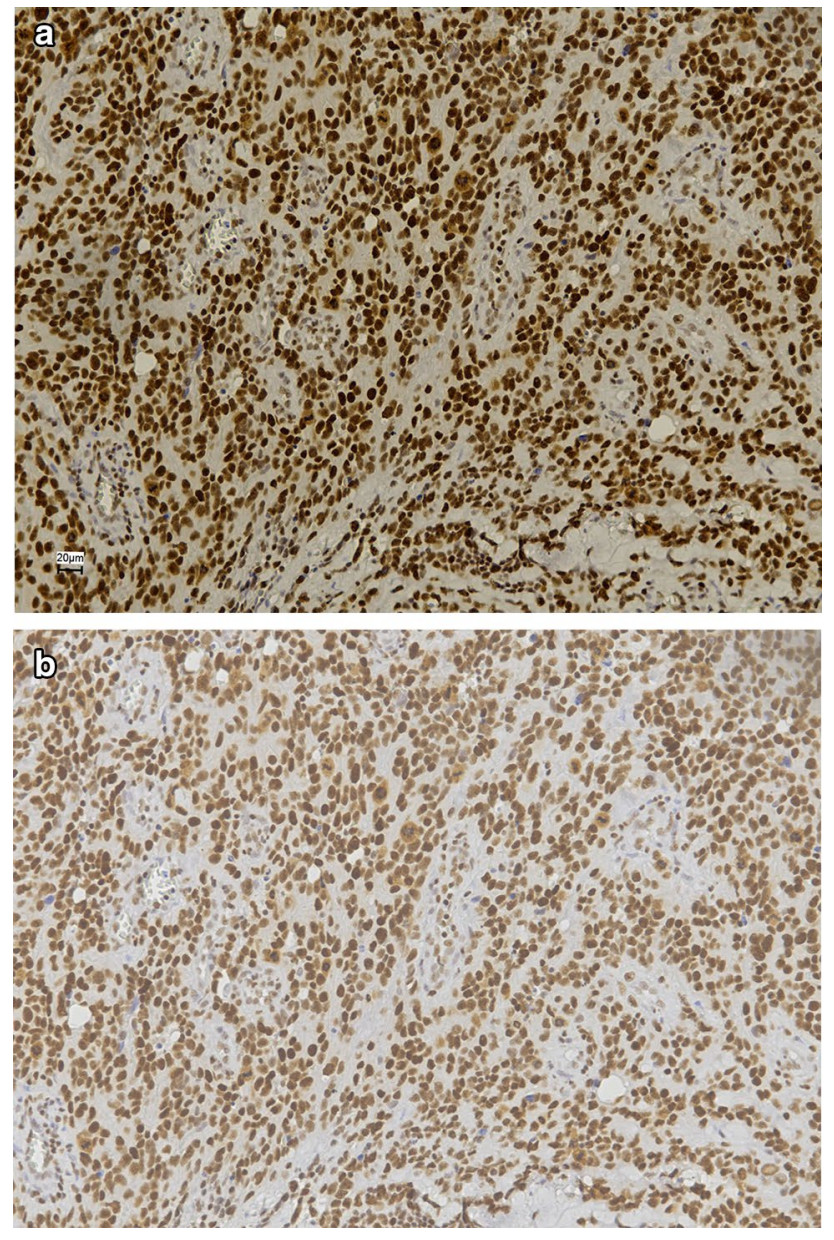

Fig. 1 Immunohistochemical expression of PARP1 and SLFN11. a UV AS sample positive for PARP1. b UV AS sample showing SLFN11 expression. Images taken at $\times 20$ digital magnification

index showed synergy $(\mathrm{CI}<1.0)$ for all combinations in MO-LAS and AS-M cells (Fig. 3c, d). The combinations with 50 and $100 \mu \mathrm{M}$ TMZ yielded even strong synergy (CI 0.1-0.3) in both cell lines except for $50 \mu \mathrm{M} \mathrm{TMZ}$ with $1 \mu \mathrm{M}$ olaparib in MO-LAS (Table 3 ). For each combination, the DRI was $>1$ for both olaparib and TMZ.

\section{Induction of DNA damage upon combination treatment}

For further analysis of the effects of the combination treatment, we aimed to investigate those combination schedules with relatively low dosages of both compounds yet resulting in a large effect on cell viability, since lower dosages will be more likely to be suited for clinical application in the future. Based on these features, we selected the combination of $50 \%$ of the $\mathrm{IC}_{50}$ of olaparib with either 50 (low dose) or $100 \mu \mathrm{M}$ (high dose) TMZ for both cell lines. Both cell lines were analyzed after $48 \mathrm{~h}$ of treatment, showing an increased level of DNA damage marker $\gamma \mathrm{H} 2 \mathrm{AX}$ after the combination treatment with both low and high dose TMZ, compared to the respective single agent treatments (Fig. 3e, f; Supplemental Fig. 3).

\section{Effects of combination treatment on apoptosis}

Next, we aimed to study the effects of the combination schedules on apoptosis. After $72 \mathrm{~h}$ and $96 \mathrm{~h}$ of treatment, both combination with low and high dose TMZ significantly induced apoptosis compared to the single agent treatments in MO-LAS and AS-M cells (Fig. 4). The level of apoptosis was significantly higher after treatment with the high-dose TMZ combinations compared to the lowdose TMZ combinations, with exception of AS-M cells after $96 \mathrm{~h}$, in which apoptosis was also increased but did not reach statistical significance.

Table 1 SLFN11 and PARP1 immunohistochemical expression per AS subtype

\begin{tabular}{llclccc}
\hline AS subtype & SLFN11+ $(\% *)$ & SLFN11- $(\% *)$ & $\begin{array}{l}\text { SLFN11 } \\
\text { Not evalu- } \\
\text { able }\end{array}$ & $\begin{array}{l}\text { PARP1+ } \\
(\%)\end{array}$ & $\begin{array}{l}\text { PARP1- } \\
(\% *)\end{array}$ & $\begin{array}{l}\text { PARP1 } \\
\text { Not evaluable }\end{array}$ \\
\hline UV AS $(n=47)$ & $37(80)$ & $9(20)$ & 1 & $46 / 47(98)$ & $1 / 47(2)$ & 0 \\
Non-UV AS $(n=96)$ & $61(66)$ & $31(34)$ & 4 & $80(93)$ & $6(7)$ \\
Cutaneous non-UV AS $(n=19)$ & $12(67)$ & $6(33)$ & 1 & $17 / 17(100)$ & 0 \\
RT AS $(n=32)$ & $20(67)$ & $10(33)$ & 2 & $29 / 32(91)$ & $3 / 32(9)$ & 0 \\
StwT AS $(n=16)$ & $10(63)$ & $6(37)$ & 0 & $10 / 10(100)$ & 0 \\
Visc AS $(n=29)$ & $19(68)$ & $9(32)$ & 1 & $24 / 27(89)$ & $3 / 27(11)$ & 2 \\
Total $(n=143)$ & $98(71)$ & $40(29)$ & 5 & $126 / 133(95)$ & $7 / 133(5)$ & 10 \\
\hline
\end{tabular}

UV AS UV-associated angiosarcoma, RT AS radiotherapy-induced angiosarcoma, StwT AS Stewart Treves angiosarcoma, Visc AS visceral angiosarcoma

*Of evaluable cases 
Table $2 \mathrm{IC}_{50}$ values for olaparib and TMZ in MO-LAS and AS-M cell lines

\begin{tabular}{llc}
\hline Cell line & Compound & $\mathrm{IC}_{50}($ mean $\pm \mathrm{SD})$ \\
\hline MO-LAS & Olaparib $(\mu \mathrm{M})$ & $1.99 \pm 0.11$ \\
& $\mathrm{TMZ}(\mu \mathrm{M})$ & $110.3 \pm 15.2$ \\
AS-M & Olaparib $(\mu \mathrm{M})$ & $6.62 \pm 1.02$ \\
& $\mathrm{TMZ}(\mu \mathrm{M})$ & $66.8 \pm 11.9$ \\
\hline
\end{tabular}

$I C_{50}$ concentration at which $50 \%$ of cell viability is affected, $S D$ standard deviation, TMZ temozolomide

\section{Discussion}

In this study, we showed that PARP1 expression was present in almost all (46/47, 98\%) UV AS samples and in both UV AS cell lines, indicating a potential role for PARP inhibition in UV AS. In addition, SLFN11 and PARP1 are present in a large proportion of non-UV AS. As expected, single agent olaparib yielded only modest effects in UV AS cell lines MO-LAS and AS-M. We therefore combined olaparib with the alkylating agent TMZ and demonstrated, synergy between olaparib and TMZ treatment in two UV AS cell lines, with strong synergy $(\mathrm{CI}<0.3)$ in nearly all combinations using 50 and $100 \mu \mathrm{M}$ TMZ. Combination treatment of olaparib and TMZ effectively induced apoptosis after $72 \mathrm{~h}$ and $96 \mathrm{~h}$ of treatment. The level of $\gamma \mathrm{H} 2 \mathrm{AX}$, indicative of DNA damage, was significantly higher upon combination treatment compared to any of the single agents.

The DRI was $>1$ for all combination treatments, indicating that the dosage of both TMZ and olaparib can be reduced in combination treatment compared to the

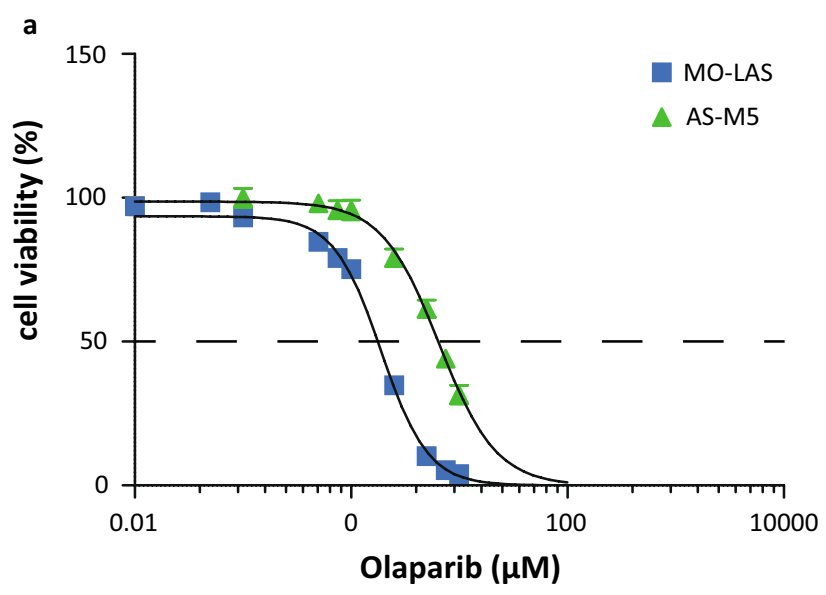

Fig. 2 Single agent therapy effects on cell viability of olaparib and TMZ. a Cell viability after treatment with olaparib for MO-LAS and AS-M cells (mean values of three experiments); b Cell viability after effects of the respective single agent treatments. Given the potential toxicity of the combination treatment, these dose reductions could contribute to better tolerability while maintaining optimal anti-cancer effects. Both UV AS cell lines showed a higher DRI for TMZ compared to the DRI for olaparib, which is in line with previous finding showing that olaparib has a potentiating effect on TMZ (Curtin and Szabo 2013). Treatment with TMZ leads to methylation of DNA at three positions: the $\mathrm{O} 6$ and N7 position of guanine and the N3-position of adenine. These methylpurines are then excised, resulting in single strand DNA breaks (SSBs). Inactivation of PARP1 inhibits repair of SSBs, thus potentiating the effect of TMZ (Curtin and Szabo 2013).

The in vitro activity of PARPi and TMZ combination treatment in UV AS is in line with previous studies of this combination in other sarcomas (Ewing sarcoma [ES], chordoma and desmoplastic small round cell tumor [DSRCT]) (Cao et al. 2019; van Erp et al. 2020; Smith et al. 2015). Both in chordoma and DSRCT moderate to strong synergy was observed, as well as increased apoptosis (Cao et al. 2019; van Erp et al. 2020). These studies showed adequate translation of in vitro-in vivo effectivity, yielding significantly reduced tumor growth upon the combination treatment. Ideally, our in vitro findings in UV AS would be further examined in an in vivo study. However, no such model is yet available, and given the concordant results in chordoma and DSRCT, it could be considered to proceed to a clinical study directly.

To date, phase II clinical studies in different malignancies such as small cell lung cancer (SCLC), melanoma and glioblastoma multiforme showed that the combination of a PARPi with TMZ was well tolerated but yielded mostly only modest responses ( $\mathrm{Lu}$ et al. 2018). The maximum reported

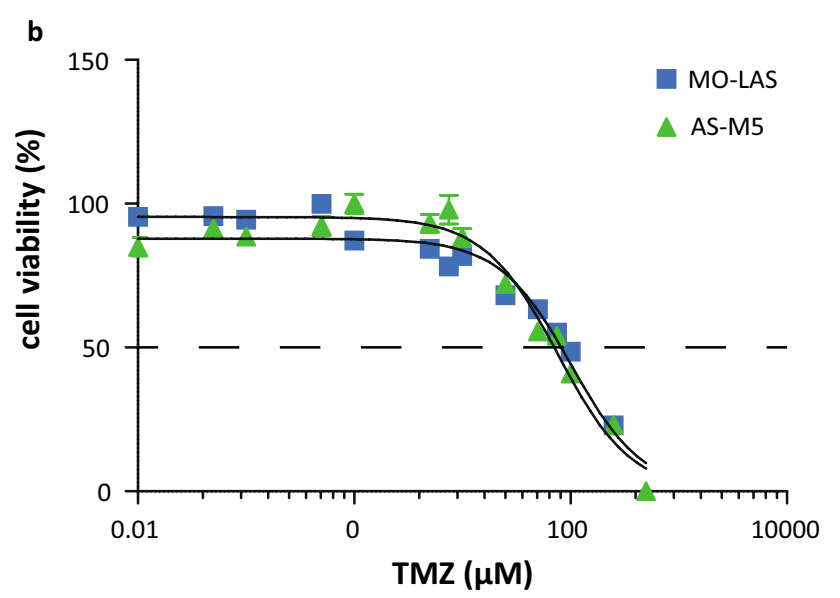

treatment with temozolomide for MO-LAS and AS-M cells (mean values of three experiments). Dotted line represents $50 \%$ reduction in cell viability $\left(\mathrm{IC}_{50}\right)$ 


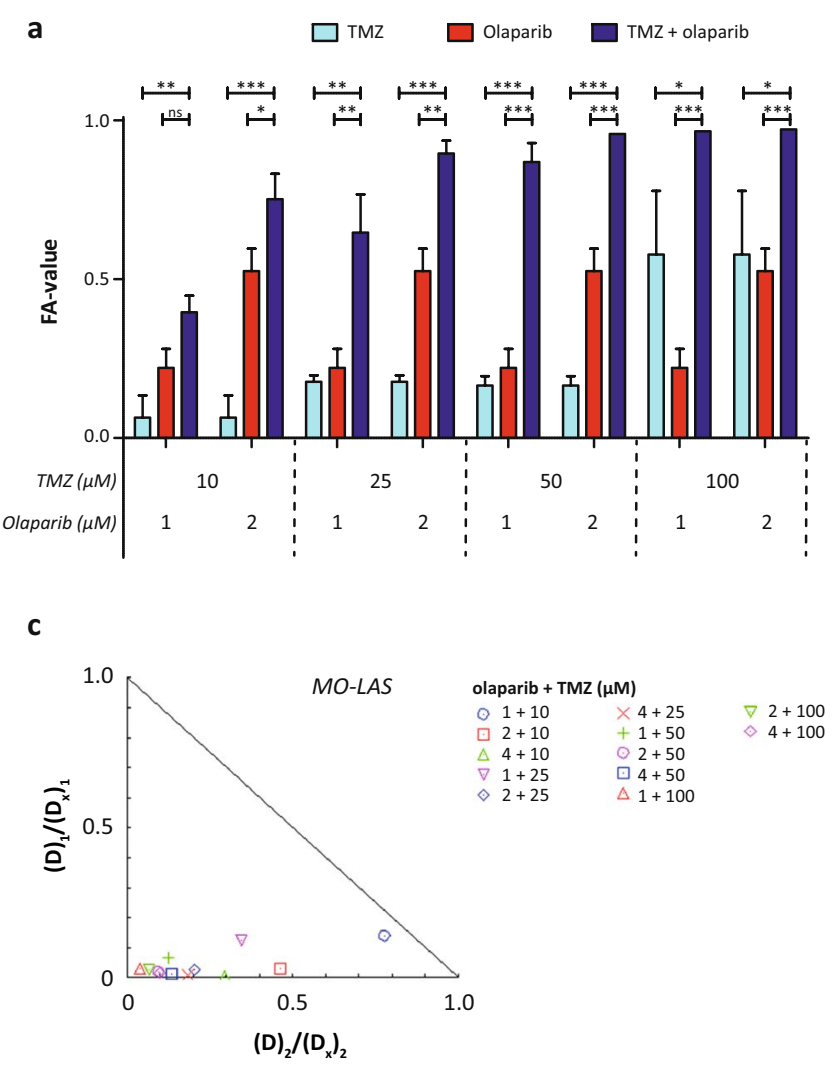

e

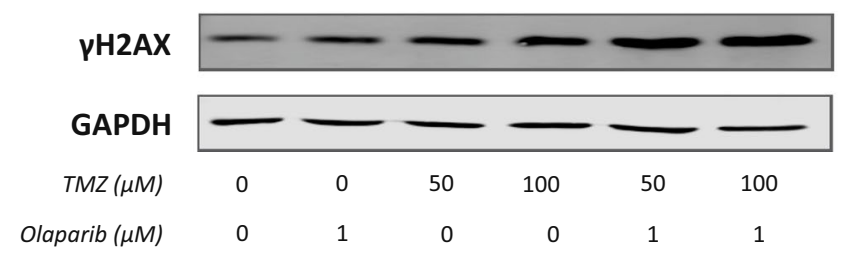

Fig. 3 Combination therapy of olaparib and TMZ in MO-LAS and AS-M cell lines. a Cell viability of MO-LAS cells treated with single agent and combination treatment. b Cell viability of AS-M cells treated with single agent and combination treatment. c Isobologram of the combination treatment with increasing olaparib and TMZ concentrations in MO-LAS cells. The $X$ - and $Y$-axis represent the fraction of the dose necessary as a single agent to generate reduction of $x \%$ cell viability $\left(D_{1 / 2}\right)$ divided by the portion of the drug in the

median PFS was 3.6 months in melanoma patients, which did not differ from response to TMZ monotherapy (Middleton et al. 2015). In ES, no antitumor activity was observed in a phase I/II trial of PARPi talazoparib and TMZ in 15 patients (Schafer et al. 2020). Of note, these patients were already heavily pre-treated (median of three previous treatments). In addition, in vivo combination treatment with

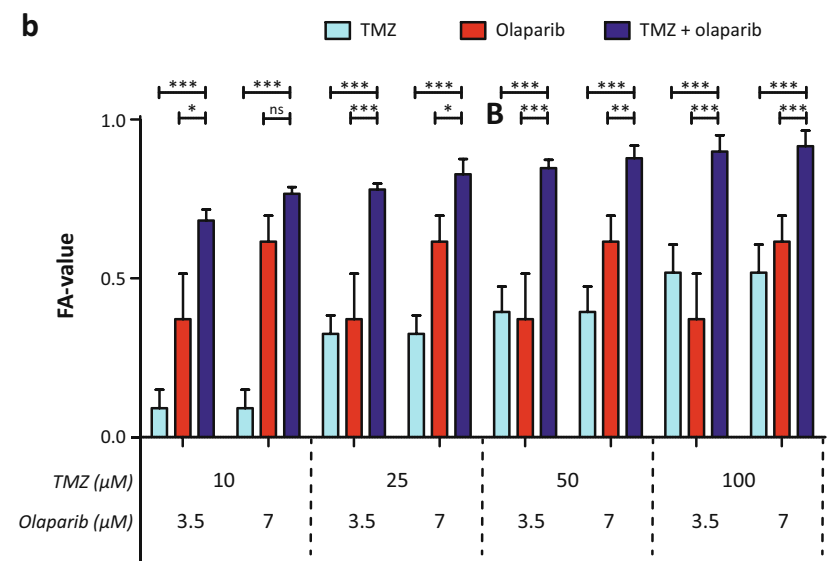

d

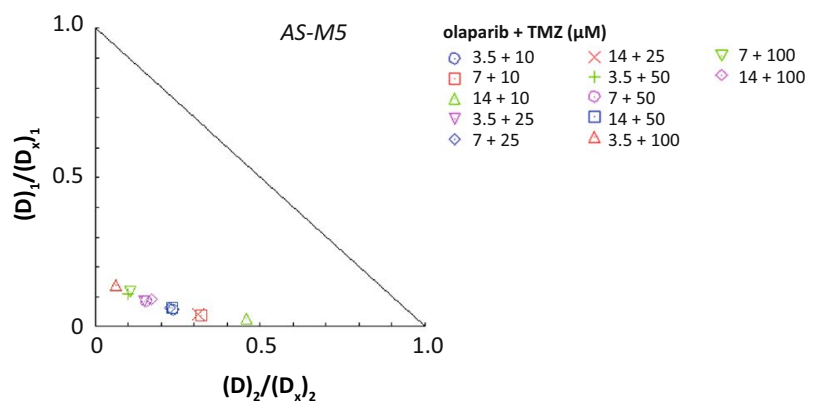

f

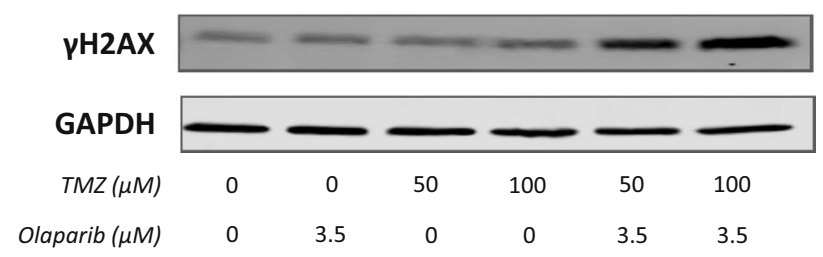

combination treatment $\left(D_{1}+D_{2}\right)$ necessary to reduce a similar $x \%$ cell viability $(D x)_{1 / 2} . D_{1}=\mathrm{TMZ}, D_{2}=$ olaparib. d Isobologram of the combination treatment with increasing olaparib and TMZ concentrations in AS-M cells. e Protein expression of $\gamma \mathrm{H} 2 \mathrm{AX}$ in MOLAS cells treated with single agent and combination treatment for $48 \mathrm{~h}$. f Protein expression of $\gamma \mathrm{H} 2 \mathrm{AX}$ in AS-M cells treated with single agent and combination treatment for $48 \mathrm{~h}$. $* p$ value $<0.05$; $* * p$ value $<0.01 ; * * *$ value $<0.001$

PARPi and TMZ in 10 ES models was only effective in 5/10 models (Smith et al. 2015). There was no clear correlation between PARP levels and responsiveness to treatment, and other biomarkers were not mentioned.

A high potential candidate biomarker for response to PARPi and chemotherapy combination treatment is Schlafen-11 (SLFN11), which was discovered to correlate 
Table 3 FA, CI and DRI values for combination treatment in MO-LAS and AS-M cell lines

\begin{tabular}{|c|c|c|c|c|c|}
\hline & Olaparib $(\mu \mathrm{M})$ & $\mathrm{TMZ}(\mu \mathrm{M})$ & $\begin{array}{l}\text { FA value } \\
(\text { mean } \pm S D)\end{array}$ & CI & DRI (TMZ; olaparib) \\
\hline \multirow[t]{8}{*}{ MO-LAS } & \multirow[t]{4}{*}{1} & 10 & 0.396 & 0.918 & $(7.1 ; 1.3)$ \\
\hline & & 25 & 0.752 & 0.494 & $(33.1 ; 2.2)$ \\
\hline & & 50 & 0.647 & 0.470 & $(8.0 ; 2.9)$ \\
\hline & & 100 & 0.896 & 0.230 & $(37.8 ; 4.9)$ \\
\hline & \multirow[t]{4}{*}{2} & 10 & 0.869 & 0.194 & $(14.5 ; 8.0)$ \\
\hline & & 25 & 0.957 & 0.117 & $(49.0 ; 10.4)$ \\
\hline & & 50 & 0.966 & 0.072 & $(31.3 ; 25.2)$ \\
\hline & & 100 & 0.972 & 0.094 & $(38.3 ; 14.8)$ \\
\hline \multirow[t]{8}{*}{ AS-M } & \multirow[t]{4}{*}{3.5} & 10 & 0.682 & 0.291 & $(18.2 ; 4.2)$ \\
\hline & & 25 & 0.766 & 0.359 & $(27.3 ; 3.1)$ \\
\hline & & 50 & 0.780 & 0.235 & $(11.8 ; 6.7)$ \\
\hline & & 100 & 0.828 & 0.290 & $(15.8 ; 4.4)$ \\
\hline & \multirow[t]{4}{*}{7} & 10 & 0.847 & 0.211 & $(9.0 ; 10.0)$ \\
\hline & & 25 & 0.878 & 0.244 & $(11.6 ; 6.4)$ \\
\hline & & 50 & 0.899 & 0.206 & $(7.1 ; 15.4)$ \\
\hline & & 100 & 0.916 & 0.224 & $(8.6 ; 9.3)$ \\
\hline
\end{tabular}

FA value fraction of cell viability affected by treatment, $S D$ standard deviation, $C I$ combination index, $D R I$ dose reduction index, $T M Z$ temozolomide with sensitivity to DNA damaging agents (Zoppoli et al. 2012; Barretina et al. 2012). In our study, SLFN11 expression was present in both UV AS cell lines and in $80 \%$ of UV AS tumor samples. Several preclinical studies provided evidence for the role of SLFN11 in cytotoxic effects of PARPi and chemotherapy in for instance Ewing sarcoma and lung cancer (Iwasaki et al. 2019; Lok et al. 2017; Tang et al. 2015). However, a recent study showed no correlation between SLFN11 expression and olaparib activity in breast cancer cell lines and PDX models (Winkler et al. 2021), stressing the need for cancer-specific experiments to examine SLFN11 as a biomarker. Thus far, the two reported clinical studies examining SLFN11 as a biomarker have not shown conclusive results. Although one study did report SLFN11 expression to be associated with a better response to TMZ/PARPi combination treatment in SCLC patients, a very low cut-off value for SLFN11 expression was used (any presence of SLFN11-positive cells) (Pietanza et al. 2018). In another trial investigating a PARPi and irinotecan with or without TMZ in solid malignancies, SLFN11 had a significant association with best response in all patients, but no association was found between the intensity of SLFN11 expression and best response (Federico et al. 2020). Hence, further studies are needed to determine the appropriate clinical application of SLFN11 as a biomarker in AS.
Due to the limited availability of evidence with regard to the appropriate threshold for SLFN11 positivity, we applied a cut-off value of $50 \%$ positive cells in the current study, aiming for a relevant level of expression. This might have resulted in an underestimation of SLFN11 positivity in UV AS cases. Although PARP1 and SLFN11 were not only present in UV AS cases but also in a large proportion of nonUV AS cases, further preclinical experiments in non-UV AS were not possible due to a lack of models.

Future research should further explore the use of SLFN11 as a biomarker in AS, starting with knockdown experiments in AS cell lines and establishment of the appropriate threshold for SLFN11 expression. Validation of SLFN11 in a clinical setting (either in AS or in other, more common cancers in which patient inclusion is less challenging) may enable the design of a biomarker-driven basket study to investigate PARPi and TMZ combination therapy in cancer patients with SLFN11-positive tumors. Ideally, such a study would only include cancer types in which in vitro results already indicate sensitivity to PARPi and TMZ treatment. Another potentially interesting development lies in the combination of PARPi with immune checkpoint inhibition (ICI), based on increased tumor mutational burden (TMB) and upregulation of Programmed Death-Ligand 1 upon PARP inhibition (Peyraud and Italiano 2020). Given the presence of PARP1 
a

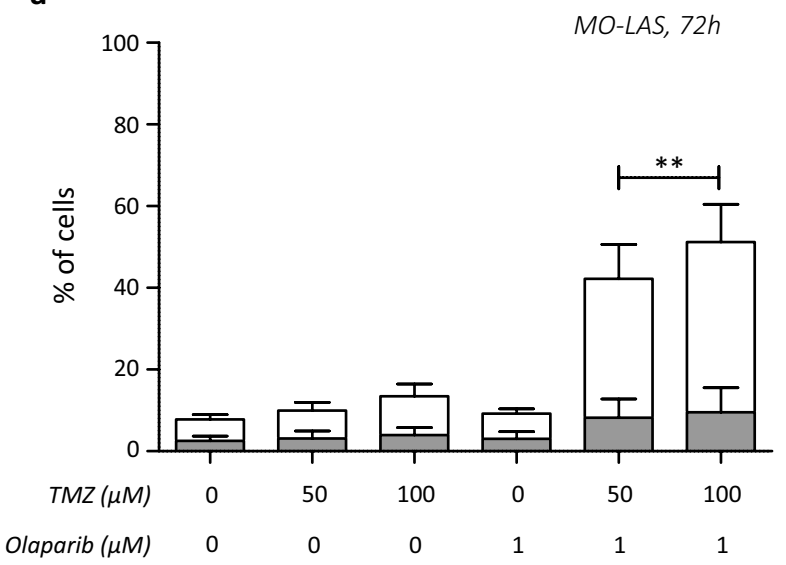

C

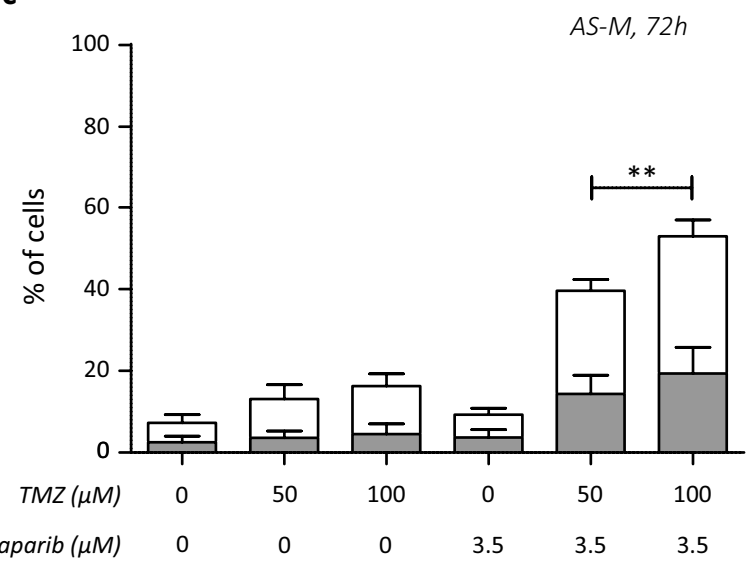

Fig. 4 Apoptosis induction after combination therapy in MOLAS and AS-M cell lines. a Induction of early and late apoptotic cells upon $72 \mathrm{~h}$ of treatment with low dose $(50 \mu \mathrm{M})$ and high dose $(100 \mu \mathrm{M}) \mathrm{TMZ}$ with olaparib in MO-LAS cells. b Induction of early and late apoptotic cells upon $96 \mathrm{~h}$ of treatment with low dose $(50 \mu \mathrm{M})$ and high dose $(100 \mu \mathrm{M})$ TMZ with olaparib in MO-LAS cells. c

expression in our study, and the previously reported high TMB and corresponding clinical response to ICI in UV AS (Painter et al. 2020), this combination treatment could also be of interest for UV AS patients.

Overall, our data show that the combination therapy of PARPi olaparib with alkylating agent TMZ works b

Early apoptosis $\square$ Late apoptosis

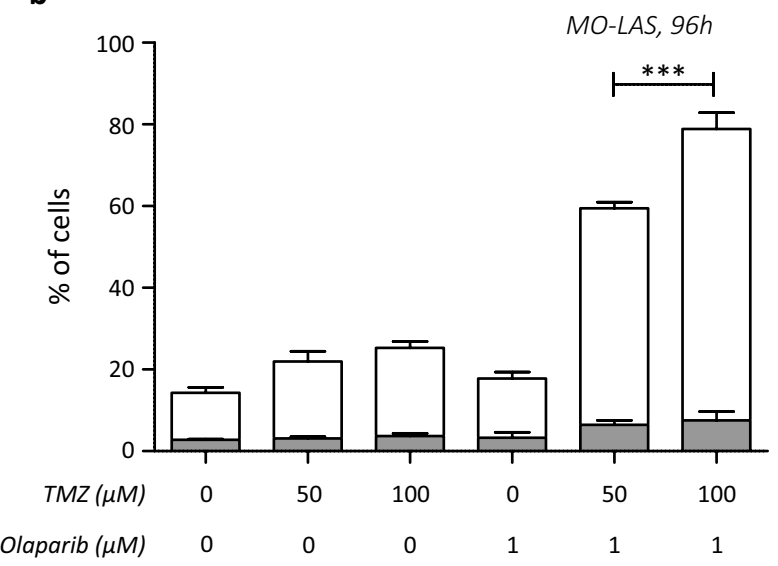

d

Early apoptosis $\square$ Late apoptosis

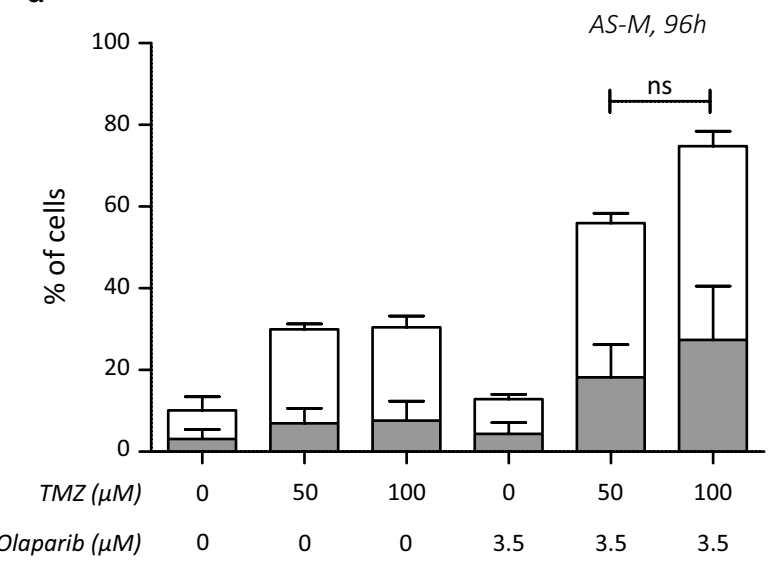

Induction of early and late apoptotic cells upon $72 \mathrm{~h}$ of treatment with low dose $(50 \mu \mathrm{M})$ and high dose $(100 \mu \mathrm{M}) \mathrm{TMZ}$ with olaparib in AS-M cells. d Induction of early and late apoptotic cells upon $96 \mathrm{~h}$ of treatment with low dose $(50 \mu \mathrm{M})$ and high dose $(100 \mu \mathrm{M}) \mathrm{TMZ}$ with olaparib in AS-M cells. * $p$ value $<0.05 ; * * p$ value $<0.01$; $* * * p$ value $<0.001$

synergistically in UV AS cell lines. In addition, we demonstrated expression of SLFN11, a biomarker for response to DNA damaging agents, in $74 \%$ of UV AS tumor samples. Therefore, these results may provide the first step towards novel AS subtype-specific targeted treatment options. 
Supplementary Information The online version contains supplementary material available at https://doi.org/10.1007/s00432-021-03678-4.

Acknowledgements The authors would like to thank dr. Mikio Masuzawa (Kitasato University School of Allied Sciences Sagamihara, Japan) for providing the MO-LAS cell line and prof. dr. James Kirkpatrick and dr. Ronald Unger (University of Mainz, Germany) for sharing the AS-M cell line with us. The authors also thank Cor Jacobs (laboratory of Experimental Internal Medicine, Radboud University Medical Center, The Netherlands), for his assistance with the use of the CytoFLEX flow cytometer. The members of PALGA-group are: J. W. R. Meyer: Rijnstate, Arnhem, The Netherlands; M. C. H. Hogenes: LABPON, Hengelo, The Netherlands.

Author contributions MEW, IMED, MHSH-R, AEMvE, UEF, WTAvdG and YMHV-J contributed to the study conception and design. Material preparation, data collection and analysis were performed by MEW, MHSH-R and YMHV-J. The first draft of the manuscript was written by MEW and all authors commented on the manuscript. All authors read and approved the final manuscript.

Funding This study was supported by the Dutch charities "Stichting Bergh in het Zadel voor de Kankerbestrijding", and "Honderd-Duizend-keer-een-Tientje (HDKT)".

Data availability Data and material are available upon request.

\section{Declarations}

Conflict of interest The authors declare that they have no conflict of interest.

Ethical approval Ethical approval for the use of patient material and data was obtained from the local certified Medical Ethics Committee of the Radboud University Medical Center, Nijmegen, The Netherlands (File number 2016-2686).

Open Access This article is licensed under a Creative Commons Attribution 4.0 International License, which permits use, sharing, adaptation, distribution and reproduction in any medium or format, as long as you give appropriate credit to the original author(s) and the source, provide a link to the Creative Commons licence, and indicate if changes were made. The images or other third party material in this article are included in the article's Creative Commons licence, unless indicated otherwise in a credit line to the material. If material is not included in the article's Creative Commons licence and your intended use is not permitted by statutory regulation or exceeds the permitted use, you will need to obtain permission directly from the copyright holder. To view a copy of this licence, visit http://creativecommons.org/licenses/by/4.0/.

\section{References}

Agulnik M, Yarber JL, Okuno SH, von Mehren M, Jovanovic BD, Brockstein BE, Evens AM, Benjamin RS (2013) An open-label, multicenter, phase II study of bevacizumab for the treatment of angiosarcoma and epithelioid hemangioendotheliomas. Ann Oncol 24:257-263. https://doi.org/10.1093/annonc/mds237

Barretina J, Caponigro G, Stransky N, Venkatesan K, Margolin AA, Kim S, Wilson CJ, Lehar J, Kryukov GV, Sonkin D, Reddy A, Liu M, Murray L, Berger MF, Monahan JE, Morais P, Meltzer J, Korejwa A, Jane-Valbuena J, Mapa FA, Thibault J, Bric-Furlong
E, Raman P, Shipway A, Engels IH, Cheng J, Yu GK, Yu J, Aspesi P Jr, de Silva M, Jagtap K, Jones MD, Wang L, Hatton C, Palescandolo E, Gupta S, Mahan S, Sougnez C, Onofrio RC, Liefeld T, MacConaill L, Winckler W, Reich M, Li N, Mesirov JP, Gabriel SB, Getz G, Ardlie K, Chan V, Myer VE, Weber BL, Porter J, Warmuth M, Finan P, Harris JL, Meyerson M, Golub TR, Morrissey MP, Sellers WR, Schlegel R, Garraway LA (2012) The Cancer Cell Line Encyclopedia enables predictive modelling of anticancer drug sensitivity. Nature 483:603-607. https://doi.org/10.1038/nature11003

Cao X, Lu Y, Liu Y, Zhou Y, Song H, Zhang W, Davis D, Cui J, Hao S, Jung J, Wu Q, Park DM, Yang C (2019) Combination of PARP inhibitor and temozolomide to suppress chordoma progression. J Mol Med 97:1183-1193. https://doi.org/10.1007/ s00109-019-01802-z

Casparie M, Tiebosch AT, Burger G, Blauwgeers H, van de Pol A, van Krieken JH, Meijer GA (2007) Pathology databanking and biobanking in The Netherlands, a central role for PALGA, the nationwide histopathology and cytopathology data network and archive. Cell Oncol 29:19-24

Chan JY, Lim JQ, Yeong J, Ravi V, Guan P, Boot A, Tay TKY, Selvarajan S, Md Nasir ND, Loh JH, Ong CK, Huang D, Tan J, Li Z, Ng CC, Tan TT, Masuzawa M, Sung KW, Farid M, Quek RHH, Tan NC, Teo MCC, Rozen SG, Tan P, Futreal A, Teh BT, Soo KC (2020) Multiomic analysis and immunoprofiling reveal distinct subtypes of human angiosarcoma. J Clin Investig. https://doi.org/10.1172/jci139080

Chou TC (2006) Theoretical basis, experimental design, and computerized simulation of synergism and antagonism in drug combination studies. Pharmacol Rev 58:621-681. https://doi.org/ 10.1124/pr.58.3.10

Choy E, Butrynski JE, Harmon DC, Morgan JA, George S, Wagner AJ, D'Adamo D, Cote GM, Flamand Y, Benes CH, Haber DA, Baselga JM, Demetri GD (2014) Phase II study of olaparib in patients with refractory Ewing sarcoma following failure of standard chemotherapy. BMC Cancer 14:813. https://doi.org/ $10.1186 / 1471-2407-14-813$

Curtin NJ, Szabo C (2013) Therapeutic applications of PARP inhibitors: anticancer therapy and beyond. Mol Asp Med 34:12171256. https://doi.org/10.1016/j.mam.2013.01.006

Farmer H, McCabe N, Lord CJ, Tutt ANJ, Johnson DA, Richardson TB, Santarosa M, Dillon KJ, Hickson I, Knights C, Martin NMB, Jackson SP, Smith GCM, Ashworth A (2005) Targeting the DNA repair defect in BRCA mutant cells as a therapeutic strategy. Nature 434:917-921. https://doi.org/10.1038/natur e03445

Federico SM, Pappo AS, Sahr N, Sykes A, Campagne O, Stewart CF, Clay MR, Bahrami A, McCarville MB, Kaste SC, Santana VM, Helmig S, Gartrell J, Shelat A, Brennan RC, Hawkins D, Godwin K, Bishop MW, Furman WL, Stewart E (2020) A phase I trial of talazoparib and irinotecan with and without temozolomide in children and young adults with recurrent or refractory solid malignancies. Eur J Cancer 137:204-213. https://doi.org/ 10.1016/j.ejca.2020.06.014

Florou V, Rosenberg AE, Wieder E, Komanduri KV, Kolonias D, Uduman M, Castle JC, Buell JS, Trent JC, Wilky BA (2019) Angiosarcoma patients treated with immune checkpoint inhibitors: a case series of seven patients from a single institution. J Immunother Cancer 7:213-313. https://doi.org/10.1186/s40425-019-0689-7

Iwasaki J, Komori T, Nakagawa F, Nagase H, Uchida J, Matsuo K, Uto $Y$ (2019) Schlafen 11 expression is associated with the antitumor activity of trabectedin in human sarcoma cell lines. Anticancer Res 39:3553-3563. https://doi.org/10.21873/anticanres.13501

Kollar A, Jones RL, Stacchiotti S, Gelderblom H, Guida M, Grignani G, Steeghs N, Safwat A, Katz D, Duffaud F, Sleijfer S, van der Graaf WT, Touati N, Litiere S, Marreaud S, Gronchi A, Kasper 
B (2017) Pazopanib in advanced vascular sarcomas: an EORTC Soft Tissue and Bone Sarcoma Group (STBSG) retrospective analysis. Acta Oncol 56:88-92. https://doi.org/10.1080/02841 86x.2016.1234068

Krump-Konvalinkova V, Bittinger F, Olert J, Brauninger W, Brunner J, Kirkpatrick CJ (2003) Establishment and characterization of an angiosarcoma-derived cell line, As-M. Endothelium 10:319-328

Lahat G, Dhuka AR, Hallevi H, Xiao L, Zou C, Smith KD, Phung TL, Pollock RE, Benjamin R, Hunt KK, Lazar AJ, Lev D (2010) Angiosarcoma: clinical and molecular insights. Ann Surg 251:1098-1106. https://doi.org/10.1097/SLA.0b013e3181dbb75a

Leichman L, Groshen S, O’Neil BH, Messersmith W, Berlin J, Chan E, Leichman CG, Cohen SJ, Cohen D, Lenz HJ, Gold P, Boman B, Fielding A, Locker G, Cason RC, Hamilton SR, Hochster HS (2016) Phase II study of olaparib (AZD-2281) after standard systemic therapies for disseminated colorectal cancer. Oncologist 21:172-177. https://doi.org/10.1634/theoncologist.2015-0319

Lok BH, Gardner EE, Schneeberger VE, Ni A, Desmeules P, Rekhtman N, de Stanchina E, Teicher BA, Riaz N, Powell SN, Poirier JT, Rudin CM (2017) PARP inhibitor activity correlates with SLFN11 expression and demonstrates synergy with temozolomide in small cell lung cancer. Clin Cancer Res 23:523-535. https://doi.org/10. 1158/1078-0432.Ccr-16-1040

Lord CJ, Ashworth A (2012) The DNA damage response and cancer therapy. Nature 481:287-294. https://doi.org/10.1038/natur e10760

Lu Y, Liu Y, Pang Y, Pacak K, Yang C (2018) Double-barreled gun: combination of PARP inhibitor with conventional chemotherapy. Pharmacol Ther 188:168-175. https://doi.org/10.1016/j.pharm thera.2018.03.006

Masuzawa M, Masuzawa M, Hamada Y, Arakawa N, Mori M, Ishii M, Nishiyama S (2012) Establishment and characterization of a novel lymphangiosarcoma cell line (MO-LAS) compared with the hemangiosarcoma cell line (ISO-HAS). Cancer Med 1:39-46. https://doi.org/10.1002/cam4.12

Middleton MR, Friedlander P, Hamid O, Daud A, Plummer R, Falotico N, Chyla B, Jiang F, McKeegan E, Mostafa NM, Zhu M, Qian J, McKee M, Luo Y, Giranda VL, McArthur GA (2015) Randomized phase II study evaluating veliparib (ABT-888) with temozolomide in patients with metastatic melanoma. Ann Oncol 26:2173-2179. https://doi.org/10.1093/annonc/mdv308

Murai J, Huang SY, Das BB, Renaud A, Zhang Y, Doroshow JH, Ji J, Takeda S, Pommier Y (2012) Trapping of PARP1 and PARP2 by clinical PARP inhibitors. Cancer Res 72:5588-5599. https://doi. org/10.1158/0008-5472.Can-12-2753

Murai J, Zhang Y, Morris J, Ji J, Takeda S, Doroshow JH, Pommier Y (2014) Rationale for poly(ADP-ribose) polymerase (PARP) inhibitors in combination therapy with camptothecins or temozolomide based on PARP trapping versus catalytic inhibition. J Pharmacol Exp Ther 349:408-416. https://doi.org/10.1124/jpet.113.210146

Murai J, Feng Y, Yu GK, Ru Y, Tang SW, Shen Y, Pommier Y (2016) Resistance to PARP inhibitors by SLFN11 inactivation can be overcome by ATR inhibition. Oncotarget 7:76534-76550. https:// doi.org/10.18632/oncotarget.12266

Murai J, Tang SW, Leo E, Baechler SA, Redon CE, Zhang H, Al Abo M, Rajapakse VN, Nakamura E, Jenkins LMM, Aladjem MI, Pommier Y (2018) SLFN11 blocks stressed replication forks independently of ATR. Mol Cell 69:371-84.e6. https://doi.org/ 10.1016/j.molcel.2018.01.012

NCIN (2012) National Cancer Intelligence Network. Soft tissue sarcoma incidence and survival; tumours diagnosed in England between 1985 and 2009. http://www.ncin.org.uk/cancer_type_ and_topic_specific_work/cancer_type_specific_work/sarcomas/. Accessed 16 April 2012

Painter CA, Jain E, Tomson BN, Dunphy M, Stoddard RE, Thomas BS, Damon AL, Shah S, Kim D, Gomez Tejeda Zanudo J, Hornick
JL, Chen YL, Merriam P, Raut CP, Demetri GD, Van Tine BA, Lander ES, Golub TR, Wagle N (2020) The Angiosarcoma Project: enabling genomic and clinical discoveries in a rare cancer through patient-partnered research. Nat Med 26:181-187. https:// doi.org/10.1038/s41591-019-0749-z

Penel N, Italiano A, Ray-Coquard I, Chaigneau L, Delcambre C, Robin YM, Bui B, Bertucci F, Isambert N, Cupissol D, Bompas E, Bay JO, Duffaud F, Guillemet C, Blay JY (2012) Metastatic angiosarcomas: doxorubicin-based regimens, weekly paclitaxel and metastasectomy significantly improve the outcome. Ann Oncol 23:517-523. https://doi.org/10.1093/annonc/mdr138

Peyraud F, Italiano A (2020) Combined PARP inhibition and immune checkpoint therapy in solid tumors. Cancers. https://doi.org/10. 3390/cancers12061502

Pietanza MC, Waqar SN, Krug LM, Dowlati A, Hann CL, Chiappori A, Owonikoko TK, Woo KM, Cardnell RJ, Fujimoto J, Long L, Diao L, Wang J, Bensman Y, Hurtado B, de Groot P, Sulman EP, Wistuba II, Chen A, Fleisher M, Heymach JV, Kris MG, Rudin CM, Byers LA (2018) Randomized, double-blind, phase II study of temozolomide in combination with either veliparib or placebo in patients with relapsed-sensitive or refractory small-cell lung cancer. J Clin Oncol 36:2386-2394. https://doi.org/10.1200/jco. 2018.77.7672

Pignochino Y, Capozzi F, D’Ambrosio L, Dell'Aglio C, Basirico M, Canta M, Lorenzato A, Vignolo Lutati F, Aliberti S, Palesandro E, Boccone P, Galizia D, Miano S, Chiabotto G, Napione L, Gammaitoni L, Sangiolo D, Benassi MS, Pasini B, Chiorino G, Aglietta M, Grignani G (2017) PARP1 expression drives the synergistic antitumor activity of trabectedin and PARP1 inhibitors in sarcoma preclinical models. Mol Cancer 16:86. https://doi.org/ 10.1186/s12943-017-0652-5

Rathkey D, Khanal M, Murai J, Zhang J, Sengupta M, Jiang Q, Morrow B, Evans CN, Chari R, Fetsch P, Chung HJ, Xi L, Roth M, Filie A, Raffeld M, Thomas A, Pommier Y, Hassan R (2020) Sensitivity of mesothelioma cells to PARP inhibitors is not dependent on BAP1 but is enhanced by temozolomide in cells with high-schlafen 11 and low-O6-methylguanine-DNA methyltransferase expression. J Thorac Oncol 15:843-859. https://doi.org/10.1016/j.jtho.2020. 01.012

Ray-Coquard I, Italiano A, Bompas E, Le Cesne A, Robin YM, Chevreau C, Bay JO, Bousquet G, Piperno-Neumann S, Isambert N, Lemaitre L, Fournier C, Gauthier E, Collard O, Cupissol D, Clisant S, Blay JY, Penel N (2012) Sorafenib for patients with advanced angiosarcoma: a phase II trial from the French Sarcoma Group (GSF/GETO). Oncologist 17:260-266. https://doi.org/10. 1634/theoncologist.2011-0237

Schafer ES, Rau RE, Berg SL, Liu X, Minard CG, Bishop AJR, Romero JC, Hicks MJ, Nelson MD Jr, Voss S, Reid JM, Fox E, Weigel BJ, Blaney SM (2020) Phase 1/2 trial of talazoparib in combination with temozolomide in children and adolescents with refractory/ recurrent solid tumors including Ewing sarcoma: a Children's Oncology Group Phase 1 Consortium study (ADVL1411). Pediatr Blood Cancer 67:e28073. https://doi.org/10.1002/pbc.28073

Smith MA, Reynolds CP, Kang MH, Kolb EA, Gorlick R, Carol H, Lock RB, Keir ST, Maris JM, Billups CA, Lyalin D, Kurmasheva RT, Houghton PJ (2015) Synergistic activity of PARP inhibition by talazoparib (BMN 673) with temozolomide in pediatric cancer models in the pediatric preclinical testing program. Clin Cancer Res 21:819-832. https://doi.org/10.1158/1078-0432.Ccr-14-2572

Stacchiotti S, Palassini E, Sanfilippo R, Vincenzi B, Arena MG, Bochicchio AM, De Rosa P, Nuzzo A, Turano S, Morosi C, Dei Tos AP, Pilotti S, Casali PG (2012) Gemcitabine in advanced angiosarcoma: a retrospective case series analysis from the Italian Rare Cancer Network. Ann Oncol 23:501-508. https://doi.org/10.1093/ annonc/mdr066 
Tang SW, Bilke S, Cao L, Murai J, Sousa FG, Yamade M, Rajapakse V, Varma S, Helman LJ, Khan J, Meltzer PS, Pommier Y (2015) SLFN11 is a transcriptional target of EWS-FLI1 and a determinant of drug response in Ewing sarcoma. Clin Cancer Res 21:4184-4193. https://doi.org/10.1158/1078-0432.Ccr-14-2112

van der Graaf WT, Blay JY, Chawla SP, Kim DW, Bui-Nguyen B, Casali PG, Schoffski P, Aglietta M, Staddon AP, Beppu Y, Le Cesne A, Gelderblom H, Judson IR, Araki N, Ouali M, Marreaud S, Hodge R, Dewji MR, Coens C, Demetri GD, Fletcher CD, Dei Tos AP, Hohenberger P (2012) Pazopanib for metastatic softtissue sarcoma (PALETTE): a randomised, double-blind, placebocontrolled phase 3 trial. Lancet 379:1879-1886. https://doi.org/ 10.1016/s0140-6736(12)60651-5

van Erp AEM, van Houdt L, Hillebrandt-Roeffen MHS, van Bree NFHN, Flucke UE, Mentzel T, Shipley J, Desar IME, Fleuren EDG, Versleijen-Jonkers YMH, van der Graaf WTA (2020) Olaparib and temozolomide in desmoplastic small round cell tumors: a promising combination in vitro and in vivo. J Cancer Res Clin Oncol 146:1659-1670. https://doi.org/10.1007/ s00432-020-03211-z

Wang L, Lao IW, Yu L, Wang J (2017) Clinicopathological features and prognostic factors in angiosarcoma: a retrospective analysis of 200 patients from a single Chinese medical institute. Oncol Lett 14:5370-5378. https://doi.org/10.3892/ol.2017.6892

Weidema ME, Flucke UE, van der Graaf WTA, Ho VKY, HillebrandtRoeffen MHS, Versleijen-Jonkers YMH, Husson O, Desar IME (2019) Prognostic factors in a large nationwide cohort of histologically confirmed primary and secondary angiosarcomas. Cancers. https://doi.org/10.3390/cancers 11111780

Weidema ME, van de Geer E, Koelsche C, Desar IME, Kemmeren P, Hillebrandt-Roeffen MHS, Ho VKY, van der Graaf WTA,
Versleijen-Jonkers YMH, von Deimling A, Flucke UE (2020) DNA methylation profiling identifies distinct clusters in angiosarcomas. Clin Cancer Res 26:93. https://doi.org/10.1158/10780432.CCR-19-2180

Winkler C, Armenia J, Jones GN, Tobalina L, Sale MJ, Petreus T, Baird T, Serra V, Wang AT, Lau A, Garnett MJ, Jaaks P, Coker EA, Pierce AJ, O'Connor MJ, Leo E (2021) SLFN11 informs on standard of care and novel treatments in a wide range of cancer models. Br J Cancer 124:951-962. https://doi.org/10.1038/ s41416-020-01199-4

Zhang J, Stevens MF, Bradshaw TD (2012) Temozolomide: mechanisms of action, repair and resistance. Curr Mol Pharmacol 5:102-114

Zhang C, Xu G, Liu Z, Xu Y, Lin F, Baklaushev VP, Chekhonin VP, Peltzer K, Mao M, Wang X, Wang G, Zhang C (2019) Epidemiology, tumor characteristics and survival in patients with angiosarcoma in the United States: a population-based study of 4537 cases. Jpn J Clin Oncol. https://doi.org/10.1093/jjco/hyz113

Zoppoli G, Regairaz M, Leo E, Reinhold WC, Varma S, Ballestrero A, Doroshow JH, Pommier Y (2012) Putative DNA/RNA helicase Schlafen-11 (SLFN11) sensitizes cancer cells to DNA-damaging agents. Proc Natl Acad Sci 109:15030. https://doi.org/10.1073/ pnas. 1205943109

Publisher's Note Springer Nature remains neutral with regard to jurisdictional claims in published maps and institutional affiliations. 